\title{
Live birth rates in different subgroups of poor ovarian responders according to Bologna criteria and POSEIDON group classification
}

\section{Mehri Mashayekhy}

Royan Institute

\section{Forouzan Barabi}

Royan Institute

Arezoo Arabipoor ( $\sim$ arezoo.arabipoor@gmail.com )

Reproductive Biomedicine Research Center, Royan Institute for Reproductive Biomedicine, ACECR, Iran, Tehran https://orcid.org/0000-0002-8535-7898

\section{Zahra Zolfaghari}

Royan Institute

\section{Research}

Keywords: Poor ovarian responders, live birth rate, Bologna criteria, POSEIDON group classification

Posted Date: March 11th, 2020

DOl: https://doi.org/10.21203/rs.3.rs-16752/v1

License: (c) (i) This work is licensed under a Creative Commons Attribution 4.0 International License. Read Full License

Version of Record: A version of this preprint was published at Journal of Gynecology Obstetrics and Human Reproduction on November 1st, 2021. See the published version at https://doi.org/10.1016/j.jogoh.2021.102169. 


\section{Abstract}

Background Recently, some studies evaluated the live births rates (LBRs) in two poor ovarian responders (POR) classification methods separately, but present study was designed to compare the LBRs among different groups of patients on the basis of Bologna criteria or POSIEDON group classifications and find the important predictive factors for LBR in patients with POR.

Methods In this cross-sectional study, the database containing clinical and laboratory information on infertility treatment cycles were evaluated from December 2015 to December 2017 and all the patients with at least one POR after standard controlled ovarian stimulation $(\mathrm{COH})$ during IVF/ICSI cycles were evaluated. The eligible patients were enrolled and divided into five and four groups according to the Bologna criteria and POSEIDON groups' classifications, respectively.

Results 812 patients with POR diagnosis were investigated which in overall 517 of them had embryo transfer in the last treatment cycle (63.6\%) and total clinical pregnancy rate $19.3 \%$ (100 cases) and live birth rates $16.1 \%$ ( 86 cases) were found. When the patients were grouped on the Basis of the POSEIDON classification, the highest LBR was observed in the POSEIDON group III. On the other hand, according to the Bologna criteria, 41 patients were not included in any group, and in the analysis of cycle outcome, the LBR in the Bologna group II was more than other groups. The multivariable regression analysis revealed that the significant independent variables remained in the model as important predictive factor for live births in the study population were the number and quality of the transferred embryos transmission (good and excellent quality), and the POSSIDON classification group (POSSIDON group III).

Conclusions On the basis of present results, the POSEIDON group classification could be more comprehensive and practical than Bologna criteria for diagnosing and categorizing POR patients. In addition, it was found the number and quality of transferred embryos were the most important prognostic factor for live birth in POR patients; therefore we suggest to consider $\mathrm{COH}$ protocols with a freezing embryos strategy, and the collection of more good quality embryos to improve the probability of a live birth.

\section{Background}

Poor ovarian response (POR) to gonadotropin stimulation associates with cycle cancellation and reduced chance of a live birth in an assisted reproduction technology (ART) program and still remains a challenging and frustrating subject for clinician and patients [1]. The definition of POR was established under the auspices of the European Society of Human Reproduction and Embryology (ESHRE), which was recorded as the Bologna criteria [2]. Prior this consensus, there is a huge heterogeneity in the study populations and approximately 41 different definitions have been applied to describe POR which was resulted in a poor predictive value of meta-analyses [3]. The Bologna criteria were a very important step in reducing the heterogeneity; however, in daily clinical practice, the relevant data supporting this definition are limited [4]. In a realistic approach, the term POR should refer to the ovarian response and therefore, 
one stimulated cycle is considered essential for the diagnosis of POR. In this regard, some publications have debated that there is a still significant degree of heterogeneity even with the Bologna criteria [5-7] and have concluded the minimal criteria of the ESHRE consensus are not 'full-scale' and may require revision and implementation [8]. Recently, the researchers from seven countries participated in the composition of the so-called POSEIDON (Patients-Oriented Strategies Encompassing IndividualizeD Oocyte Number) to determine a classification for POR patients and four subgroups have been suggested on the basis of age, ovarian biomarkers and previous ovarian response [9]. The marker of success according to the POSEIDON stratification is the number of retrieved oocytes required to obtain at least one euploid embryo for transfer in each individual patient [7].

Some studies evaluated live birth rates in different subgroups of POR patients fulfilling the Bologna criteria and found similar live birth in different subgroups[10, 1, 11, 12]; furthermore, these studies reported that the independent significant variables related to the live birth rate were women' age $[10,11]$ and the number of oocytes retrieved[12]. Only one study compared the live birth rates in different subgroups of POR patients on the basis of the POSEIDON classification and reported that the live birth rates (LBR) were significantly higher in POSEIDON group 1 and 2 compared with the other groups; the authors assumed that good ovarian reserve in these groups lead to a better ART outcome [9]. It seems that a study that compares live birth rates in different subgroups of Bologna criteria and POSEIDON classification and it is necessary to evaluate the predictive variables of live birth in these patients.

Present study was designed to evaluate the assisted reproductive technology (ART) outcome among various subgroups of PORs according to the POSEIDON stratification and the Bologna criteria and to determine most important predictive values for success rate after ART cycles in these patients.

\section{Materials And Methods}

In this cross-sectional study, the database containing clinical and laboratory information on infertility treatment cycles at the Endocrinology and Female Infertility Department of Royan Institute were evaluated from December 2015 to December 2017.The study protocol was approved by the Institutional Review Board and Ethics Committee of Royan Institute. The data were collected retrospectively from the registered database of the institute. The patients' data were included for analysis only when all the following inclusion criteria were contained: (1) history of at least one poor ovarian response (total number of retrieved oocytes $\leq 3$ ) after standard controlled ovarian stimulation during IVF/ICSI cycles, (2) complete patient records on basic, clinical, ART cycle characteristics, and reproductive outcome after IVF, (3) availability of at least one measurement between AMH and/ or AFC in the 3 months before commencing ovarian stimulation and (4) the ovarian reserve measurements were performed in Royan Institute before entry in the ART programme. The exclusion criteria were premature ovarian failure (basal follicle stimulating hormone (FSH) $\geq 25 \mathrm{IU} / \mathrm{l})$, donor/recipient treatments, and azoospermic male partner with testicular or epididymal sperm aspiration. 
Poor ovarian response was defined according to the Bologna criteria and existence of at least two of the following criteria: 1 ) a previous history of POR (retrieved oocytes $\leq 3$ ) in a conventional stimulation protocol, 2) Anamnestic risk factors: advanced maternal age ( $\geq 40$ years), evidence of ovarian endometrioma at the basal ultrasound, previous ovarian surgery, previous chemotherapy, genetic abnormalities, shortening of the menstrual cycle and 3) abnormal ovarian reserve tests (ORT) (i.e. antral follicle count (AFC) between $<5$ and $<7$ follicles or anti-Müllerian hormone $(\mathrm{AMH})$ between $0.5-$ $1.1 \mathrm{ng} / \mathrm{ml}$ ). Five different phenotypes of POR may be defined from the different combinations of the Bologna criteria: I) a previous poor response and presence of anamnestic risk factors, II) a previous POR and abnormal markers of ovarian reserve, III) the presence of anamnestic risk factors and abnormal markers of ovarian reserve, IV) the presence of a previous POR, anamnestic risk factors and abnormal markers of ovarian reserve, and V) two previous history of POR.

In addition, the patients were categorized in four groups on the basis of POSEIDON group classification [7]: Group 1: young patients (<35 years) with normal pre-stimulation ovarian reserve parameters (AFC $\geq 5$, $\mathrm{AMH} \geq 1.2 \mathrm{ng} / \mathrm{mL}$ ) and with an unexpected poor (<4 oocytes retrieved) or sub-optimal ovarian response (4-9 oocytes retrieved) to standard $\mathrm{COH}$. Group 2: older patients ( $\geq 35$ years) with normal pre-stimulation ovarian reserve parameters $(A F C \geq 5, A M H \geq 1.2 \mathrm{ng} / \mathrm{mL}$ ) and with an unexpected poor or suboptimal ovarian response. Group 3: the patients < 35 years with poor ovarian reserve pre-stimulation parameters $(A F C<5, A M H<1.2 \mathrm{ng} / \mathrm{mL})$. Group 4: the patients $\geq 35$ years with poor ovarian reserve pre-stimulation parameters $(\mathrm{AFC}<5, \mathrm{AMH}<1.2 \mathrm{ng} / \mathrm{mL})$.

The ovarian stimulation protocol was selected on the basis of the women's age, ORT and the results of the previous cycles if it is available. The ovarian stimulation protocols for these patients were including standard or stop $\mathrm{GnRH}$ agonist protocol, GnRH antagonist with $\mathrm{E}_{2}$ priming [13] and double mild stimulation in same cycle which had described in detail previously [14]. When at least one follicles measuring $\geq 18 \mathrm{~mm}$ in diameter was observed the final stage of oocyte maturation was induced by two pre-filled syringes of recombinant human chorionic gonadotropin (rhCG) (Ovitrelle®, $250 \mu \mathrm{g} / 0.5 \mathrm{ml}$, Merck, Serono, Inc) or with 10000 IU of hCG (Choriomon, IBSA). If this criterion has not been achieved after 10-12 days stimulation, the cycle has been cancelled for inadequate response. Transvaginal ultrasound-guided oocyte retrieval was performed 34-36 h after oocyte triggering. ICSI or IVF/ICSI was performed in all patients to prevent infrequent cases of fertilization failures with only conventional IVF. Embryos were cultured in G1v5 Plus media (Vitrolife) until the day of transfer. The obtained embryos were replaced by an embryo transfer catheter (Guardia ${ }^{\top}{ }^{M}$, Access ET Catheter, Cook Medical), 3 or 5 days after oocytes retrieval. Embryo quality was determined according to the number and regularity of blastomeres and the degree of embryonic fragmentation that has been explained previously [15]. Meanwhile, in some patients all embryos were frozen, the procedure of embryo freezing (vitrification method) [16] and FET cycles has been described in detail previously [14]. All patients in fresh ET cycles received luteal phase support in the form of 400 mg vaginal progesterone suppository twice daily (Cyclogest® (400 mg), Actavis, Barnstaple, UK) starting on the evening of the oocyte retrieval and it was continued for 10 weeks 
in cases with positive pregnancy test. A serum B-hCG analysis was done 14 days after ET, and the clinical pregnancy (presence of gestational sac with heartbeat) was determined by ultrasound scan 14 days later.

The main outcomes were the comparison of ART outcomes among different POR phenotypes patients according to Bologna criteria and POSEIDON group classification, respectively. In addition, the predictive variables for live births in patients with POR diagnosis were evaluated as secondary outcome.

\section{Statistical analysis}

The statistical analysis was carried out by using Statistical Package for the Social Sciences, version 20, SPSS Inc, Chicago, Illinois, USA (SPSS). The differences between two groups were analyzed using the independent $\mathrm{t}$-test and Mann-Whitney $\mathrm{U}$ test for the normal and non-normal continuous variables respectively. The Chi- square test was applied for comparison of the categorical variables between groups. Descriptive data are presented as mean \pm standard deviation (SD) or median (interquartile range) as indicated. The possible significant variables were entered in the multivariable logistic regression model to identify the most significant prognostic factors for live birth in the studied population. The Statistical significance level was set at $p$-value $<0.05$.

\section{Results}

One thousand and one hundred patients underwent IVF/ICSI cycles with at least one poor ovarian response were recorded in the institute database during the study. Eight hundred and twelve eligible patients were enrolled and divided into five groups according to the Bologna criteria; 41 patients were not included in any of the Bologna subgroups, since they had only one cycle less than 4 retrieved oocytes after standard ovarian stimulation without any other risk factor of POR. The number of patients in group III and IV was higher than others and the phenotype III $(58.9 \%)(n=478)$ was the most of the patients according to Bologna criteria.

\section{The comparison of different POR patient groups on the basis of Bologna criteria}

We compared baseline characteristics among different POR groups according to Bologna criteria and the results are shown in Table I. There were significant differences among groups in terms of women's age, the number of previous IVF/ICSI cycles serum AMH level and AFC before starting stimulation; however, this is expected, because these variables are determinative factors in the Bologna definition. The Bologna group IV had the highest rate of secondary infertility compared to other groups $(P<0.001)$. Also, the Bologna group $V$ had a significant difference with other groups regarding the causes of infertility; patients in this group had the lower rate of the ovulatory factor for infertility than those of other groups $(\mathrm{P}<$ 0.001). The number of patients with previous history of no oocyte and no response in the Bologna group I and II was significantly lower than other groups $(P<0.001$ and $P=0.02)$. No significant difference was found among groups regarding the others baseline characteristic variables (Table I). 
The outcomes of the last cycle of ovarian stimulation and embryo transfer were compared among different POR groups according to Bologna criteria in Table II. The ovarian stimulation protocol in the Bologna group IV was different with other groups and the most used protocols in this group were antagonists and double-stimulation protocols. In our institute $\mathrm{COH}$ protocol was selected on the basis of women' age, ovarian reserve and history of previous cycles and therefore in patients with advanced age and low ovarian reserve or previous history of POR, it was more likely to use the antagonist or doublestimulation protocol. Although the duration of ovarian stimulation and dose of used gonadotropin ( $\mathrm{rFSH}$ and/or HMG) and the number of follicles $\geq 15 \mathrm{~mm}$ on the day of oocyte triggering in the last cycle were not different among groups. Tukey analysis demonstrated that the number of retrieved and MII oocytes in Bologna group III was different from other groups and consequently the number and quality of obtained embryos and the number of embryos transferred was different from other groups $(P<0.001)$. However, the stage the transferred embryo (blastocyst or cleavage) did not differ between the groups. The cancellation and no oocyte rates were in Bologna groups IV and $\mathrm{V}$ were significantly higher than other groups $(P<0.001$ and $P=0.007)$. Endometrial thickness on the trigger day was significantly different between groups and the Bonferroni test demonstrated that endometrial thickness in Bologna groups IV were significantly higher than those of in Bologna group II and III ( $P=0.003$ and $P=0.01$, respectively). Finally, the clinical pregnancy and live birth rates in Bologna group II and III were significantly higher than other groups $(P=0.006)$.

\section{The comparison of different POR patient according to POSEIDON group classification}

When patients were classified on the basis of POSEIDON group criteria, the most of them were in the POSEIDON group IV $(57 \%)(n=463)$. Table III shows the baseline characteristics of the studied patients in different groups on the basis of POSEIDON group classification.

In similar way, there were significant differences among groups in terms of women's age, the basal FSH and serum AMH level and AFC before starting stimulation; however, this is expected, because these variables are main factors in the POSEIDON group classification. Women in POSEIDON group 4 had significantly secondary infertility type in comparison to other groups. Also, there was a significant difference in the cause of infertility between POSIDON group 1 and other groups $(P<0.001)$; the majority of patients in POSEIDON group 1 were with male factor diagnosis, whereas the most patients were diagnosed with ovarian factor in the other groups. No significant difference was found among groups in terms of the others baseline characteristic variables (Table III).

Table IV demonstrates the outcomes of the last treatment cycle of the studied patients in different groups on the basis of POSEIDON group classification. In similar way, $\mathrm{COH}$ protocol was selected on the basis of women's age, ORT and previous history; therefore, the antagonist and double-stimulation $\mathrm{COH}$ protocols have been used more frequently in patients in the POSEIDON group IV $(P<0.001)$. Although, the means of ovarian stimulation day and dose of used gonadotropins and the number of follicles $\geq 15 \mathrm{~mm}$ on the day of oocyte triggering had no significant difference among groups. Tukey analysis showed that the number 
of retrieved and MII oocytes in POSEIDON group III were than those of in in POSEIDON group IV $(P=0.002$ and $P=0.001$, respectively); meanwhile, the differences between others groups were not statistically significant. Although the number of embryos obtained and the number of embryos transferred were not in line with the total retrieved oocytes and these were significantly lower in POSEIDON group I than those of in the other three groups $(P=0.002, P=0.003$ and $P=0.008)$. In addition, the quality of obtained embryos and the rates of fertilization, cancellation as well as no- oocyte cases were not significantly different between groups. Endometrial thickness on the trigger day in POSEIDON group III were significantly higher than that of in POSEIDON group IV $(P=004)$. Finally, the clinical pregnancy and live birth rates in POSEIDON group III were significantly higher than other groups $(P=0.006)$.

Table $\mathrm{V}$ shows the association between the possible related factors with the live birth rate using univariate logistic regression test. The analysis indicated that the women age, duration of infertility, serum level TSH, the number of oocytes obtained and MII oocytes and the number of embryos obtained and the number and quality of transferred embryos and the POSSIDON classification group showed a significant unilateral relationship with the live birth rate.

All the significant possible related variables with the live birth rate were in multivariate logistic regression model. The analysis revealed that the significant independent variables remained in the model as important predictive factor for live births in the study population were the number and quality of the transferred embryos transmission (good and excellent quality), and the POSSIDON classification group (POSSIDON group III). In other words, the likelihood of a live birth after transferring excellent embryos is approximately 5.9 times higher than fair quality embryos. Also, with increasing the number of transferred embryos, the likelihood of a live birth was increased by 1.6 times. In this regression model, the likelihood of the live birth in patients in the POSSIDON group III was 3 times higher than that of in the POSSIDON group IV (Table VI).

\section{Discussion}

In the present study, 812 patients with POR diagnosis were investigated which in overall 517 of them had embryo transfer in the last treatment cycle (63.6\%) and total clinical pregnancy rate $19.3 \%$ (100 cases) and live birth rates $16.1 \%$ (86 cases) were found. When the patients were grouped on the basis of the POSEIDON classification, the highest live birth rate was observed in the POSEIDON group III. On the other hand, according to the Bologna criteria, 41 patients were not included in any group, and in the analysis of cycle outcome, the live birth rate in the Bologna group II was more than other groups. It is noteworthy that the POSEIDON classification groups were significant predictive factor for live birth in the multivariable regression analysis. According to univariate regression analysis the women age $\geq 35$ years was associated with $60 \%$ decreased likelihood of live birth; it can be interpreted that in POSEIDON group classification the age cut-off point (35 years) was significant factor in predicting live birth. It is suggested that POSEIDON group classification to be more comprehensive and practical than Bologna criteria for diagnosing and categorizing POR patients. 
In the similar way, La Marca and colleagues (2015) compared the live birth rates in 210 POR patients in different Bologna groups and reported same poor prognosis for all groups. Elsewhere Busnelli et al. (2015), in a retrospective study, evaluated 362 patients with POR diagnosis in different group according to Bologna criteria and reported the live birth rate $(6 \%)$, which were similarly poor among different groups of Bologna criteria. In their study, positive predictive factors of live birth were previous deliveries and previous chemotherapy, but age, serum AMH, serum FSH and AFC were not significantly associated with live birth. Of course, this study suggested using the Bologna criteria for designing future studies in this area. Similarly, Bozdag and colleagues (2017) in a retrospective study compared live birth rates in 821 patients in different Bologna groups and found no statistically significant difference in the rate of live births. In contrast to previous studies, Li and colleagues (2017) retrospectively evaluated 132 women undergoing the second IVF treatment cycle, who diagnosed as POR by the Bologna criteria. In this study, women aged $\geq 40$ years and/or having history of endometriosis or ovarian surgery were taken as Bologna 1; those having 3 or less oocytes retrieved in the previous IVF cycle stimulated with a standard protocol were considered as Bologna 2, while those with AFC $\leq 6$ were classified as Bologna 3.They concluded that the POR patients fulfilling different combinations of the Bologna criteria hadn't similar IVF outcomes. The best ovarian response and live-birth rate were observed in those with Bologna $1+2$ with normal AFC, and the worse in those with Bologna $1+2+3$.

In a recent study, Eftekhar et al. (2018) in a retrospective study evaluate live birth rates in 245 POR patients in different group on the basis of POSEIDON group classification and concluded the live birth rates in groups I and II were higher than those of in groups III and IV. In thier study the ovarian stimulation protocol (microdose agonist flare-up) was used in all study groups and the authors mentioned that in contrast to previous studies, which reported women age as the most important predictor of ART success, in their study the ovarian reserve factor (AMH And AFC) were the main predictive factors. In present study, we found no relationship between live birth rates and different ovarian stimulation protocols in our study population by univariate regression analysis; this issue is challenging subject in the management of POR patients. Youssef et al. in a multicenter randomized trial concluded that a mild ovarian stimulation strategy in women with poor ovarian reserve undergoing IVF leads to similar ongoing pregnancy rates as a conventional ovarian stimulation strategy [17]. In similar way, Pilehvari and colleagues have suggested that minimal stimulation protocol with lower gonadotropin used could be considered as a patient-friendly and cost-effective substitute for PORs [18]. In present study number and quality of transferred embryos were the important related variables with probability of live birth in POR patients, so we suggest pooling method for collecting more oocytes and embryos by consecutive minimal stimulation protocols to improve the success rate in POR patients.

In line with our study results, Haung and colleagues (2018) evaluated 1957 patient with a diagnosis of diminished ovarian reserve. In their study, the patient's age, the number and quality of the transfer embryos are the most predictive factors of live birth in this population. In addition, Xu et al. (2018) in a recent study evaluate the cumulative live birth (CLBR) rates in more than 3,000 patients with poor ovarian response: a 15-year survey of final in vitro fertilization outcome. They reported that the CLBR decreased from $22 \%$ for women $\leq 30$ years to $18.3 \%$ for women aged $31-34$ years, $17.2 \%$ for $35-37$ years, $13.5 \%$ 
for $38-40$ years, $10.5 \%$ for $41-43$ years, and $4.4 \%$ among women $>43$ years in the conservative analysis; therefore, an optimistic estimate in these patients is a challenging subject for clinicians.

The strengths of the study are the high sample size of POR patients and also presented the cycle outcomes according to two main diagnostic criteria in this field. As limitation of present study, we could not apply the same protocol $\mathrm{COH}$ for all POR patients according to our institute policy; individual $\mathrm{COH}$ protocols considering the age and ovarian reserve and the previous patient's treatment cycles. Therefore, the multivariable logistic regression analysis was used to determine the main predictive factors for live birth rate in $\mathrm{POR}$ patients.

On the basis of present results, the high prevalence of the POR patients according to Bologna criteria and POSEIDON group classification were in group III and IV and the most of clinical trial studies should designed to improve cycle outcomes in these patients. In addition, in present study, was found the number and quality of transferred embryos were the most important prognostic factor for live birth in POR patients; therefore we suggest to consider $\mathrm{COH}$ protocols with a freezing embryos strategy, and the collection of more good quality embryos to improve the probability of a live birth.

\section{Abbreviations}

AFC; antral follicle count; AMH:anti-Müllerian hormone; $\mathrm{COH}$ :controlled ovarian hyperstimulation; ET:embryo transfer; $\mathrm{E}_{2}$ :estradiol; FSH:follicle stimulating hormone; $\mathrm{GnRH}$ :gonadotropin-releasing hormone; HMG:human menopausal gonadotropins; hCG:human chorionic gonadotropin; IVF/ICSI:In vitro fertilization/ Intra-cytoplasmic sperm injection; ORT:ovarian reserve test; POSEIDON:Patients-Oriented Strategies Encompassing IndividualizeD Oocyte Number; POR:poor ovarian response; SD:standard deviation;

\section{Declarations}

\section{Ethics approval and consent to participate:}

The Institutional Review Boards and the Ethics Committees of Royan Institute, Tehran, Iran approved this study (ethics code: IR.ACECR.ROYAN.REC.1395.136). All procedures performed in studies involving human participants were in accordance with the ethical standards of Royan Institute and the 1964 Helsinki declaration and its later amendments or comparable ethical standards. The eligible patients signed written informed consent prior to participation in the study.

\section{Consent for publication}

Not applicable.

\section{Availability of data and materials}

The datasets used and/or analyzed during the current study are available from the corresponding authors on reasonable request. 


\section{Funding}

The study didn't have any funding support

\section{Competing interests}

All authors have nothing to disclose.

\section{Authors' contributions}

$M M, A A$ : designing the research. $F B, M M$, and $A A$ contributed in patient's selection, data collection, interpretation of data and manuscript writing/editing. MM and AA wrote the manuscript. ZZ helped in the analysis of the data. All authors read and approved the final manuscript.

\section{Acknowledgments}

We would like to thank all the participants and co-workers in Royan Institute for their assistance in this study, especially Mrs. Azam Sanati for data entering in the statistical software.

\section{Authors' information}

1. Department of Endocrinology and Female Infertility, Reproductive Biomedicine Research Center, Royan Institute for reproductive biomedicine, ACECR, Tehran, Iran.

2. Department of Epidemiology and Reproductive Health, Reproductive Epidemiology Research Center, Royan Institute for Reproductive Biomedicine, ACECR, Tehran, Iran.

\section{References}

1. La Marca A, Grisendi V, Giulini S, Sighinolfi G, Tirelli A, Argento C, et al. Live birth rates in the different combinations of the Bologna criteria poor ovarian responders: a validation study. J Assist Reprod Genet. 2015;32(6):931-7. Epub 2015/05/01.

2. Ferraretti AP, La Marca A, Fauser BC, Tarlatzis B, Nargund G, Gianaroli L. ESHRE consensus on the definition of 'poor response' to ovarian stimulation for in vitro fertilization: the Bologna criteria. Hum Reprod. 2011;26(7):1616-24. Epub 2011/04/21.

3. Polyzos NP, Devroey P. A systematic review of randomized trials for the treatment of poor ovarian responders: is there any light at the end of the tunnel? Fertil Steril. 2011;96(5):1058-61 e7. Epub 2011/11/01.

4. Busnelli A, Papaleo E, Del Prato D, La Vecchia I, lachini E, Paffoni A, et al. A retrospective evaluation of prognosis and cost-effectiveness of IVF in poor responders according to the Bologna criteria. Hum Reprod. 2015;30(2):315-22. Epub 2014/11/30.

5. Papathanasiou A. Implementing the ESHRE 'poor responder'criteria in research studies: methodological implications. Human Reproduction. 2014;29(9):1835-8. 
6. Humaidan P, Alviggi C, Fischer R, Esteves SC. The novel POSEIDON stratification of 'Low prognosis patients in Assisted Reproductive Technology'and its proposed marker of successful outcome. F1000Research. 2016;5.

7. Alviggi C, Andersen CY, Buehler K, Conforti A, De Placido G, Esteves SC, et al. A new more detailed stratification of low responders to ovarian stimulation: from a poor ovarian response to a low prognosis concept. Fertil Steril. 2016;105(6):1452-3. Epub 2016/02/28.

8. Ferraretti AP, Gianaroli L. The Bologna criteria for the definition of poor ovarian responders: is there a need for revision? Human Reproduction. 2014;29(9):1842-5.

9. Eftekhar M, Mirhashemi ES, Tabibnejad N. Outcome of assisted reproductive technology in different subgroups of poor ovarian responders fulfilling the POSEIDON criteria. Middle East Fertility Society Journal. 2018;23(4):399-403.

10. Polyzos NP, Nwoye M, Corona R, Blockeel C, Stoop D, Haentjens P, et al. Live birth rates in Bologna poor responders treated with ovarian stimulation for IVF/ICSI. Reprod Biomed Online. 2014;28(4):469-74. Epub 2014/03/04.

11. Bozdag G, Polat M, Yarali I, Yarali H. Live birth rates in various subgroups of poor ovarian responders fulfilling the Bologna criteria. Reprod Biomed Online. 2017;34(6):639-44.

12. Chai J, Lee VC-Y, Yeung TW-Y, Li RW-H, Ho P-C, Ng EH-Y. Live birth and cumulative live birth rates in expected poor ovarian responders defined by the Bologna criteria following IVF/ICSI treatment. PLoS One. 2015;10(3):e0119149.

13. Ashrafi M, Arabipoor A, Yahyaei A, Zolfaghari Z, Ghaffari F. Does the "delayed start" protocol with gonadotropin-releasing hormone antagonist improve the pregnancy outcome in Bologna poor responders? a randomized clinical trial. Reprod Biol Endocrinol. 2018;16(1):018-0442.

14. Madani T, Hemat M, Arabipoor A, Khodabakhshi SH, Zolfaghari Z. Double mild stimulation and egg collection in the same cycle for management of poor ovarian responders. J Gynecol Obstet Hum Reprod. 2019;48(5):329-33.

15. Hardarson T, Hanson C, Sjögren A, Lundin K. Human embryos with unevenly sized blastomeres have lower pregnancy and implantation rates: indications for aneuploidy and multinucleation. Human Reproduction. 2001;16(2):313-8.

16. Rezazadeh Valojerdi M, Eftekhari-Yazdi P, Karimian L, Hassani F, Movaghar B. Vitrification versus slow freezing gives excellent survival, post warming embryo morphology and pregnancy outcomes for human cleaved embryos. J Assist Reprod Genet. 2009;26(6):347-54. Epub 2009/06/11.

17. Youssef M, Van Wely M, Al-Inany H, Madani T, Jahangiri N, Khodabakhshi S, et al. A mild ovarian stimulation strategy in women with poor ovarian reserve undergoing IVF: a multicenter randomized non-inferiority trial. Human Reproduction. 2016;32(1):112-8.

18. Pilehvari S, ShahrokhTehraninejad E, Hosseinrashidi B, Keikhah F, Haghollahi F, Aziminekoo E. Comparison pregnancy outcomes between minimal stimulation protocol and conventional GnRH antagonist protocols in poor ovarian responders. Journal of family \& reproductive health. 2016;10(1):35. 


\section{Tables}

Page $12 / 25$ 
Table I: Baseline characteristics different POR groups according to Bologna criteria. Data are mean $+\mathrm{SD}$ or number (\%)

\section{POR categories}

$\begin{array}{lllll}\text { Group I } & \text { Group II } & \text { Group III } & \text { Group IV } & \text { Group V } \\ \text { (Anamnestic } & \text { (One } & \text { (Anamnestic } & \text { (Anamnestic } & \text { (Two } \\ \text { risk factors } & \text { previous } & \text { risk factors } & \text { risk factors }+ & \text { previous } \\ + \text { One } & \text { POR }+ & + \text { abnormal } & \text { One previous } & \text { POR after } \\ \text { previous } & \text { abnormal } & \text { ORT) } & \text { POR }+ & \text { standard } \\ \text { POR) } & \text { ORT) } & & \text { abnormal } & \text { COH } \\ & & & \text { ORT) } & \text { protocol) }\end{array}$

No. of

patients

$$
30 \text { (3.7) }
$$

$57(7)$

$478(58.9)$

$154(19)$

$52(6.4)$

Age (yr)

$39.4 \pm 4.3$

$38.8 \pm$ 4.8

$34.5 \pm 4.1$

$42.6 \pm 1.4$

$34.8 \pm 5.7$

$<0.001$

Menarche

age (yrs)

$13.3 \pm 1.6$

$13.1 \pm$

$12.7 \pm 1.5$

$12.8 \pm 1.6$

$12.9 \pm 1.2$

0.21

Duration of

$8.8 \pm 7.1$

$8.9 \pm 6.5$

$8.2 \pm 4.9$

$9.0 \pm 7.7$

$8.0 \pm 4.4$

0.53

marriage

$\begin{array}{lll}\text { Day } 2 \text { or } 3 & 9.0 \pm 3.9 & 8.0 \pm \\ \text { serum FSH } & & 3.172 \\ \text { (IU/ml) } & & \end{array}$

\section{Day 2 or 3}

$5.7 \pm 2.3$

$4.9 \pm 2.7 \quad 5.0 \pm 3.1$

$8.6 \pm 4.1$

$9.1 \pm 4.3$

$7.3 \pm 2.8$

0.51

serum LH

$(\mathrm{IU} / \mathrm{ml})$

\begin{tabular}{|c|c|c|c|c|c|c|}
\hline $\mathrm{AMH}(\mathrm{ng} / \mathrm{ml})$ & $1.5 \pm 0.4$ & $0.6 \pm 0.3$ & $0.5 \pm 0.375$ & $0.463 \pm 0.3$ & $1.8 \pm 0.8$ & $<0.001$ \\
\hline Total AFC & $7.8 \pm 2.902$ & $6.0 \pm 2.4$ & $6.1 \pm 3.1$ & $5.1 \pm 2.8$ & $6.7 \pm 3.0$ & $<0.001$ \\
\hline $\begin{array}{l}\text { Left ovary } \\
\text { size }\left(\mathrm{mm}^{2}\right)\end{array}$ & $\begin{array}{l}813.3 \pm \\
523.9\end{array}$ & $\begin{array}{l}569.7 \pm \\
220.4\end{array}$ & $\begin{array}{l}703.4 \pm \\
498.8\end{array}$ & $662.2 \pm 376.4$ & $\begin{array}{l}613.3 \pm \\
239.9\end{array}$ & 0.32 \\
\hline $\begin{array}{l}\text { Right ovary } \\
\text { size }\left(\mathrm{mm}^{2}\right)\end{array}$ & $\begin{array}{l}602.5 \pm \\
189.1\end{array}$ & $\begin{array}{l}749.6 \pm \\
364.9\end{array}$ & $\begin{array}{l}698.5 \pm \\
506.8\end{array}$ & $548.8 \pm 171.3$ & $\begin{array}{l}607.3 \pm \\
268.4\end{array}$ & 0.16 \\
\hline $\begin{array}{l}\text { Duration of } \\
\text { infertility } \\
\text { (yr) }\end{array}$ & $5.8 \pm 6.2$ & $6.7 \pm 5.6$ & $6.0 \pm 4.5$ & $6.7 \pm 7.0$ & $5.9 \pm 4.5$ & 0.64 \\
\hline
\end{tabular}

Type of

infertility

\begin{tabular}{|c|c|c|c|c|c|c|}
\hline Primary & $22(73.3)$ & $44(77.1)$ & $366(76.5)$ & $92(59.7)$ & $42(80.7)$ & \\
\hline Secondary & $8(26.6)$ & $13(22.8)$ & $112(23.4)$ & $62(40.2)$ & $10(19.2)$ & \\
\hline \multirow{3}{*}{$\begin{array}{l}\text { Cause of } \\
\text { infertility }\end{array}$} & & & & & & $<0.001$ \\
\hline & \multirow[t]{2}{*}{$13(43.3)$} & $22(38.5)$ & $221(46.2)$ & $85(55.1)$ & $14(26.9)$ & \\
\hline & & & Page 13/25 & & & \\
\hline
\end{tabular}




\begin{tabular}{|lllllll|} 
Ovulatory F & $2(6.66)$ & $9(15.7)$ & $85(17.7)$ & $4(2.59)$ & $13(25)$ & \\
\cline { 2 - 5 } $\begin{array}{l}\text { Male factor } \\
\text { Mix }\end{array}$ & $15(50)$ & $26(45.6)$ & $172(35.9)$ & $65(42.2)$ & $25(48.0)$ & \\
\hline $\begin{array}{l}\text { No. of } \\
\text { previous IUI } \\
\text { cycles }\end{array}$ & $1.1 \pm 2.2$ & $0.6 \pm 0.9$ & $0.8 \pm 1.3$ & $0.5 \pm 0.9$ & $0.6 \pm 1.1$ & 0.32 \\
$\begin{array}{l}\text { No. of } \\
\text { previous } \\
\text { IVF/ICSI } \\
\text { cycles }\end{array}$ & $2.3 \pm 1.3$ & $2.1 \pm 1.3$ & $2.1 \pm 1.4$ & $2.2 \pm 1.4$ & $3.1 \pm 2.0$ & 0.005 \\
$\begin{array}{l}\text { No. of } \\
\text { previous } \\
\text { cycle with no } \\
\text { oocyte }\end{array}$ & $0(0)$ & 2 & $78(16.3)$ & $34(22.0)$ & $11(21.1)$ & $<0.001$ \\
$\begin{array}{l}\text { No. of } \\
\text { previous } \\
\text { cycle with } \\
\text { no response }\end{array}$ & $2(6.66)$ & $1(1.81)$ & $70(14.7)$ & $17(11.0)$ & 9 & \\
\hline
\end{tabular}

POR: Poor ovarian response; ORT: ovarian reserve tests; $\mathrm{COH}$ : controlled ovarian hyperstimulation; SD: standard deviation 
Table II: The outcome of the last treatment cycle in different groups according to Bologna criteria. Data are mean + SD or number (\%)

Variables POr categories

\begin{tabular}{|c|c|c|c|c|}
\hline Group I & Group II & Group III & Group IV & \\
\hline $\begin{array}{l}\text { (Anamnestic } \\
\text { risk factors } \\
\text { for POR }+ \\
\text { One previous } \\
\text { POR) }\end{array}$ & $\begin{array}{l}\text { (One } \\
\text { previous } \\
\text { POR }+ \\
\text { abnormal } \\
\text { ORT) }\end{array}$ & $\begin{array}{l}\text { (Anamnestic } \\
\text { risk factors } \\
\text { for POR + } \\
\text { abnormal } \\
\text { ORT) }\end{array}$ & $\begin{array}{l}\text { (Anamnestic } \\
\text { risk factors for } \\
\text { POR + One } \\
\text { previous POR } \\
+ \text { abnormal } \\
\text { ORT) }\end{array}$ & $\begin{array}{l}\text { (Two } \\
\text { previous } \\
\text { POR after } \\
\text { standard } \\
\text { COH } \\
\text { protocol) }\end{array}$ \\
\hline $30(3.7 \%)$ & $57(7 \%)$ & $478(58.9 \%)$ & $154(19 \%)$ & $52(6.4 \%)$ \\
\hline
\end{tabular}

Type of $\mathrm{COH}$

protocol

Long

$\begin{array}{lllll}12(40 \%) & \begin{array}{l}19(34.5 \\ \%)\end{array} & 142(29.8 \%) & 13(8.4 \%) & 19(36.5 \\ & & & \%)\end{array}$

Antagonist

$14(46.7 \%)$

$31(56.4$

Double-

stimulation

$4(13.3 \%)$

$\%)$

$219(45.9 \%) \quad 85(55.2 \%)$

19(36.5

$5(8.7 \%)$

$100(20.9 \%)$

$50(32.4 \%)$

12(23.4

Mini flare

$0(0 \%)$

$0(0 \%)$

$16(3.4 \%)$

$6(3.9 \%)$

$\%)$

Duration of

stimulation

$10.2 \pm 1.39$

$9.5 \pm$

0.68

$9.327 \pm 0.41$

$8.77 \pm 0.58$

$2(3.9 \%)$

(days)

Total dosage

of $\mathrm{rFSH}$ used

$23 \pm 27.6$

$44 \pm 30.9 \quad 326 \pm 27.5$

$83 \pm 27.0$

$30 \pm 24.7$

0.22

(IU)

Total dosage

of HMG used

$19 \pm 10.6$

$28 \pm 12.3 \quad 281 \pm 11.3$

$88 \pm 12.6$

$31 \pm 10.7$

0.56

(IU)

Number of follicles ( $\geq$

$15 \mathrm{~mm}$ ) on

hCG day

No. of

retrieved

oocytes

No. of

metaphase II

oocytes

No. of

obtained
$2.6 \pm 0.4$

$2.8 \pm$

0.55

$1.89 \pm 0.15$

$1.84 \pm 0.21$

$1.44 \pm$

0.24
$8.22 \pm$

1.06
0.71

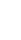


embryo

$\begin{array}{lllllll}\begin{array}{l}\text { Fertilization } \\ \text { rate }\end{array} & 0.76 \pm 0.35 & 0.58 \pm & 0.575 \pm 0.40 & 0.51 \pm 0.44 & 0.57 \pm & 0.07 \\ & & 0.31 & & & 0.40 & \end{array}$

\section{Cycle} cancellation;

$0(0 \%)$

0(0 \%)

$22(4.60 \%) \quad 13(8.44 \%)$

$6(11.5 \%) \quad<0.001$

$\mathrm{n}(\%)$

No oocyte

$0(0 \%)$

$0(0 \%)$

$47(9.83 \%) \quad 22(14.2 \%)$

$8(15.3 \%)$

0.006

Fertilization
failure; $\mathrm{n}(\%)$

All freeze for $5(16.6 \%)$ $5(8.77 \%)$ $101(21.1 \%)$ $30(19.4 \%)$ $6(11.5 \%)$

0.11

poor $3(5.26 \%) \quad 11(2.30 \%) \quad 3(1.94 \%)$ $4(7.69 \%)$ endometrium;

$\mathrm{n}(\%)$

$\begin{array}{rllllll}\begin{array}{c}\text { Type of } \\ \text { embryo }\end{array} & 19(79.1 \%) & 38 & 238(80.1 \%) & 59(68.6 \%) & \begin{array}{l}19 \\ (67.8 \%)\end{array} & 0.3 \\ \text { transfer } & & (77.5 \%) & & & \end{array}$

Fresh

$\begin{array}{lllllll}\text { Frozen } & 5(20.9 \%) & \begin{array}{l}11 \\ (22.5 \%)\end{array} & 59(19.9 \%) & 27(31.4 \%) & 9(32.2 \%) & \\ \begin{array}{l}\text { No. of } \\ \text { embryos } \\ \text { transferred }\end{array} & 1.95 \pm 0.75 & \begin{array}{l}2.34 \pm \\ 0.75\end{array} & 1.90 \pm 0.77 & 1.65 \pm 0.664 & \begin{array}{l}1.48 \pm \\ 0.57\end{array} & <0.001 \\ \begin{array}{l}\text { Stage of } \\ \text { embryo } \\ \text { transferred }\end{array} & 20(83.3 \%) & \begin{array}{l}42(85.7 \\ \%)\end{array} & 264(88.5 \%) & 77(89.5 \%) & \begin{array}{l}25(86.2 \\ \%)\end{array} & 0.47 \\ \end{array}$

Cleavage

stage

Blastocyst

$4(16.6 \%) \quad 7(14.2 \%) \quad 34(11.4 \%) \quad 9(10.4 \%) \quad 4(13.7 \%)$

Stage

Quality of

embryos

Excellent

Good

Fair

Endometrium

thickness on

trigger day

Implantation $\quad 0.5 \pm 0.1$ rate

$1(4.16 \%)$

$9.0 \pm 1.7$
$22(91.6 \%)$

$27(55.1$

$\%)$

$1(4.16 \%)$

16(32.6

$\%)$

104(34.8 \%) $\quad 30(34.8 \%)$

$139(46.6 \%) \quad 39(45.3 \%)$

$12(42.9$

$\%)$

10(35.7

$\%)$

$6(12.2 \%) \quad 55(18.4 \%)$

$17(19.7 \%)$

$6(21.4 \%)$

$9.0 \pm 1.5 \quad 8.8 \pm 1.7$

$8.4 \pm 1.5$

$8.5 \pm 1.4$

0.013

0.007 


\begin{tabular}{llllllc}
$\begin{array}{l}\text { Clinical } \\
\text { pregnancy } \\
\text { rate /ET }\end{array}$ & $3 / 24(12.5 \%)$ & $\begin{array}{l}10 / 49 \\
(20.4 \%)\end{array}$ & $\begin{array}{l}69 / 297 \\
(23.2 \%)\end{array}$ & $5 / 86(5.81 \%)$ & $\begin{array}{l}3 / \\
28(10.7 \\
\%)\end{array}$ & 0.006 \\
$\begin{array}{l}\text { Blighted } \\
\text { ovum rate/ET }\end{array}$ & $0(0 \%)$ & $1(2.04 \%)$ & $4(1.34 \%)$ & $3(3.48 \%)$ & $1(3.57 \%)$ & 0.045 \\
$\begin{array}{l}\text { Abortion rate } \\
\text { /ET }\end{array}$ & $2(8.33 \%)$ & $1(2.04 \%)$ & $10(3.36 \%)$ & $1(1.16 \%)$ & $0(0 \%)$ & 0.17 \\
$\begin{array}{l}\text { Live birth rate } \\
\text { /ET }\end{array}$ & $1 / 24(4.2 \%)$ & $\begin{array}{l}9 / 49 \\
(18.3 \%)\end{array}$ & $\begin{array}{l}59 / 297 \\
(19.8 \%)\end{array}$ & $5 / 86(5.81 \%)$ & $\begin{array}{l}3 / 28 \\
(10.7 \%)\end{array}$ & 0.006 \\
\hline
\end{tabular}


Table III: Baseline characteristics different POR groups according to POSEIDON group classification. Data are mean +SD or number (\%)

POR categories

Group I Group II Group III Group IV

$($ Age $<35+\quad($ Age $\geq 35+\quad$ (Age $<35+$ normal ORT+ normal ORT+ abnormal

Variable oocyte retrieved $<9)$

oocyte retrieved $<9)$

ORT+oocyte

retrieved <5)

(Age $\geq 35+$ abnormal

ORT+oocyte

retrieved <5)

No. of

$50(6.2 \%)$

75(\%9. 2)

$224(27.6 \%)$

$463(57 \%)$

patients

Age (yr)

$30.5 \pm 2.9$

$39.8 \pm 2.9$

$30.5 \pm 2.9$

$39.4 \pm 3.0$

$<0.001$

Menarche

$12.9 \pm 1.32$

$13.0 \pm 1.3$

$12.8 \pm 1.5$

$12.8 \pm 1.6$

0.73

age (yrs)

Duration

$7.7 \pm 3.6$

$8.6 \pm 6.4$

$7.0 \pm 3.3$

$9.163 \pm 6.5$

0.11

of

marriage

Basal FSH $\quad 7.58 \pm 3.0$

$7.9 \pm 3.4$

$8.3 \pm 4.0$

$8.9 \pm 4.1$

0.03

serum

level

Basal LH

serum

$5.1 \pm 3.346$

$5.2 \pm 3.1$

$4.7 \pm 2.8$

$5.1 \pm 3.1$

0.60

level

\begin{tabular}{|c|c|c|c|c|c|}
\hline $\begin{array}{l}\text { Basal } \\
\text { AMH } \\
\text { serum } \\
\text { level }\end{array}$ & $1.9 \pm 1.2$ & $1.84 \pm 1.2$ & $0.5 \pm 0.04$ & $0.5 \pm 0.01$ & $<0.001$ \\
\hline $\begin{array}{l}\text { Antral } \\
\text { follicle } \\
\text { count }\end{array}$ & $7.4 \pm 2.8$ & $7.3 \pm 2.8$ & $6.3 \pm 3.1$ & $5.7 \pm 3.0$ & $<0.001$ \\
\hline $\begin{array}{l}\text { Left ovary } \\
\text { size } \\
\left(\mathrm{mm}^{2}\right)\end{array}$ & $728.1 \pm 460.3$ & $679.7 \pm 353.4$ & $680.4 \pm 477.3$ & $686.4 \pm 447.6$ & 0.70 \\
\hline $\begin{array}{l}\text { Right } \\
\text { ovary size } \\
\left(\mathrm{mm}^{2}\right)\end{array}$ & $631.5 \pm 301.4$ & $634.3 \pm 344.0$ & $674.3 \pm 410.5$ & $669.2 \pm 455.8$ & 0.74 \\
\hline $\begin{array}{l}\text { Duration } \\
\text { of } \\
\text { infertility } \\
(y r)\end{array}$ & $6.1 \pm 3.8$ & $5.9 \pm 5.7$ & $5.3 \pm 3.4$ & $6.7 \pm 5.9$ & 0.30 \\
\hline \multirow{2}{*}{$\begin{array}{l}\text { Type of } \\
\text { infertility }\end{array}$} & $42(84 \%)$ & $55(73.3 \%)$ & 191 (85.3 \%) & $314(67.8 \%)$ & \multirow[t]{2}{*}{$<0.001$} \\
\hline & 8 (16\%) & $20(26.7 \%)$ & $33(14.7 \%)$ & $149(32.2 \%)$ & \\
\hline
\end{tabular}




\begin{tabular}{|c|c|c|c|c|c|}
\hline $\begin{array}{l}\text { Cause of } \\
\text { infertility }\end{array}$ & $11(22 \%)$ & $30(40 \%)$ & $90(40.1 \%)$ & $237(51.2 \%)$ & $<0.001$ \\
\hline $\begin{array}{l}\text { Ovarian } \\
\text { factor }\end{array}$ & $21(42 \%)$ & $10(13.3 \%)$ & $54(24.1 \%)$ & $46(9.95 \%)$ & \\
\hline \multirow{2}{*}{$\begin{array}{l}\text { Male } \\
\text { factor }\end{array}$} & & & & & \\
\hline & $18(36 \%)$ & $35(46.6 \%)$ & $80(35.7 \%)$ & 179(38.7 \%) & \\
\hline \multicolumn{6}{|l|}{ Mixed } \\
\hline $\begin{array}{l}\text { No. of } \\
\text { previous } \\
\text { IUl cycles }\end{array}$ & $0.8 \pm 1.2$ & $0.6 \pm 1.5$ & $0.8 \pm 1.2$ & $0.6 \pm 1.1$ & 0.13 \\
\hline $\begin{array}{l}\text { No. of } \\
\text { previous } \\
\text { IVF.ICSI } \\
\text { cycles }\end{array}$ & $2.4 \pm 1.7$ & $2.4 \pm 1.7$ & $2.1 \pm 1.2$ & $2.2 \pm 1.5$ & 0.89 \\
\hline $\begin{array}{l}\text { No. of no } \\
\text { oocyte } \\
\text { history }\end{array}$ & $6(12 \%)$ & $6(8 \%)$ & $30(13.5 \%)$ & $83(18 \%)$ & 0.85 \\
\hline $\begin{array}{l}\text { No. of no } \\
\text { response } \\
\text { history }\end{array}$ & $8(16 \%)$ & $9(12 \%)$ & $35(15.7 \%)$ & $54(11.8 \%)$ & 0.48 \\
\hline
\end{tabular}

POR: Poor ovarian response; ORT: ovarian reserve tests; $\mathrm{COH}$ : controlled ovarian hyperstimulation; SD: standard deviation 
Table IV: The outcome of the last treatment cycle in different groups according to POSEIDON group classification. Data are mean + SD or number $(\%)$.

POR categories

\begin{tabular}{|c|c|c|c|c|c|}
\hline Variable & $\begin{array}{l}\text { Group I } \\
(\text { Age<35 }+ \\
\text { normal ORT+ } \\
\text { oocyte } \\
\text { retrieved }<9)\end{array}$ & $\begin{array}{l}\text { Group II } \\
(\text { Age } \geq 35+ \\
\text { normal ORT+ } \\
\text { oocyte } \\
\text { retrieved }<9)\end{array}$ & $\begin{array}{l}\text { Group III } \\
\text { (Age<35+ } \\
\text { abnormal ORT+ } \\
\text { oocyte retrieved } \\
<5)\end{array}$ & $\begin{array}{l}\text { Group IV } \\
(\text { Age } \geq 35+ \\
\text { abnormal ORT+ } \\
\text { oocyte retrieved } \\
<5)\end{array}$ & $\begin{array}{l}P \\
\text { value }\end{array}$ \\
\hline No. of patients & $50(6.2 \%)$ & $75(\% 9.2)$ & $224(27.6 \%)$ & $463(57 \%)$ & \\
\hline $\begin{array}{l}\text { Type of } \\
\text { ovarian } \\
\text { stimulation } \\
\text { protocol }\end{array}$ & $23(46 \%)$ & $33(44 \%)$ & $77(34.4 \%)$ & $92(20 \%)$ & $<0.001$ \\
\hline \multicolumn{6}{|l|}{ Long } \\
\hline Antagonist & $22(44 \%)$ & $29(38.7 \%)$ & $102(45.5 \%)$ & $235(51.1 \%)$ & \\
\hline $\begin{array}{l}\text { Double- } \\
\text { stimulation } \\
\text { protocol }\end{array}$ & $5(10 \%)$ & $11(14.6 \%)$ & $36(16.1 \%)$ & $120(26 \%)$ & \\
\hline Mini-flare & $0(0 \%)$ & $2(2.7 \%)$ & $9(4 \%)$ & $13(2.9 \%)$ & \\
\hline $\begin{array}{l}\text { Duration of } \\
\text { stimulation } \\
\text { (days) }\end{array}$ & $7.6 \pm 3.6$ & $9.5 \pm 2.9$ & $10.3 \pm 3.6$ & $8.8 \pm 2.7$ & 0.13 \\
\hline $\begin{array}{l}\text { Total dosage } \\
\text { of rFSH used } \\
\text { (IU) }\end{array}$ & $24.8 \pm 7.7$ & $26.5 \pm 10.9$ & $26.7 \pm 10.9$ & $28.5 \pm 12.0$ & 0.14 \\
\hline $\begin{array}{l}\text { Total dosage } \\
\text { of hMG used } \\
\text { (IU) }\end{array}$ & $8.3 \pm 4.6$ & $12.51 \pm 7.0$ & $11.14 \pm 6.5$ & $11.9 \pm 7.9$ & 0.07 \\
\hline $\begin{array}{l}\text { Number of } \\
\text { follicles ( } \geq 15 \\
\text { mm) on hCG } \\
\text { day }\end{array}$ & $7.6 \pm 3.6$ & $9.5 \pm 2.9$ & $10.3 \pm 3.6$ & $8.8 \pm 2.7$ & 0.35 \\
\hline $\begin{array}{l}\text { No. of retrieved } \\
\text { oocytes }\end{array}$ & $1.6 \pm 0.5$ & $1.9 \pm 1.1$ & $2.4 \pm 1.3$ & $1.9 \pm 1.2$ & 0.005 \\
\hline $\begin{array}{l}\text { No. of } \\
\text { metaphase II } \\
\text { oocytes }\end{array}$ & $2.6 \pm 1.7$ & $2.5 \pm 1.9$ & $2.9 \pm 2.1$ & $2.3 \pm 1.9$ & 0.002 \\
\hline Number of $\mathrm{Ml}$ & $1.8 \pm 1.2$ & $2.2 \pm 1.7$ & $2.4 \pm 1.9$ & $1.9 \pm 1.7$ & 0.15 \\
\hline Number of GV & $0.3 \pm 0.7$ & $0.1 \pm 0.3$ & $0.2 \pm 0.5$ & $0.2 \pm 0.5$ & 0.44 \\
\hline $\begin{array}{l}\text { No. of } \\
\text { obtained }\end{array}$ & $1.5 \pm 0.5$ & $2.5 \pm 1.4$ & $2.3 \pm 1.1$ & $2.1 \pm 1.1$ & 0.001 \\
\hline
\end{tabular}


embryo

Cycle

cancellation; $\mathrm{n}$

$0(0 \%)$

$6(8 \%)$

$13(5.8 \%)$

$22(4.75 \%)$

0.22

(\%)

No oocyte rate; $\quad 3(6 \%)$

$\mathrm{n}(\%)$

Fertilization

failure; $\mathrm{n}(\%)$

All freeze for $\quad 2(4 \%)$

poor

endometrium;

n (\%)

Type of embryos

transfer

Fresh

Frozen

$4(10.3 \%)$

$1.4 \pm 0.5$

No. of

embryos

transferred

Stage of

embryo

$35(89.7 \%)$

$5(6.66 \%)$

$19(8.48 \%)$

$50(10.7 \%)$

0.46

$6(12 \%)$

$17(22.6 \%)$

$38(16.9 \%)$

$93(20.0 \%)$

0.36

4(5.33\%)

$6(2.67 \%)$

$9(2.0 \%)$

0.52

35 (89.7\%)

$33(76.7 \%)$

$126(85.1 \%)$

210 (72.6\%)

0.08

transferred

Cleavage

stage

$4(10.3 \%)$

10(23.3 \%)

17(11.4\%)

36 (12.5\%)

Blastocyst

Stage

Quality of

embryos

Excellent

14(35.8 \%)

$9(20.9 \%)$

$54(36.2 \%)$

102(35.3 \%)

Good

Fair

$7(17.9 \%)$

$5(11.6 \%)$

26(18.1\%)

$48(16.6 \%)$

Endometrium

$9.0 \pm 1.4$

$8.9 \pm 1.6$

$9.080 \pm 1.9$

$8.6 \pm 1.5$

0.019

trigger day

Fertilization

rate

Implantation

rate

Clinical

$5 / 39(12.8 \%) \quad 5 / 43(11.6 \%) \quad$ 43/148 $(29.0$

47/289 $(16.3$

$0.56 \pm 0.4$

0.93

$0.5 \pm 0.3$

$0.5 \pm 0.4$

$0.5 \pm 0.3$

$0.6 \pm 0.2$

$0.56 \pm 0.2$

0.58

$0.5 \pm 0.2$ 


\begin{tabular}{|c|c|c|c|c|c|}
\hline $\begin{array}{l}\text { pregnancy rate } \\
\text {.ET }\end{array}$ & & & $\%)$ & $\%)$ & \\
\hline $\begin{array}{l}\text { Blighted ovum } \\
\text { rate/ET }\end{array}$ & $1 / 39(2.5 \%)$ & $0(0 \%)$ & $3 / 148(2.0 \%)$ & $5 / 289(1.7 \%)$ & 0.81 \\
\hline $\begin{array}{l}\text { Abortion rate } \\
\text { /ET }\end{array}$ & $0 / 39 \quad(0 \%)$ & $1 / 43(2.3 \%)$ & $3 / 148(2.0 \%)$ & $10 / 289 \quad(3.4 \%)$ & 0.57 \\
\hline $\begin{array}{l}\text { Live birth } \\
\text { rate/ET }\end{array}$ & $5 / 39(12.8 \%)$ & $4 / 43(9.3 \%)$ & $40 / 148(27 \%)$ & $37 / 289$ (12.8\%) & 0.001 \\
\hline
\end{tabular}

POR: Poor ovarian response; ORT: ovarian reserve tests; $\mathrm{COH}$ : controlled ovarian hyperstimulation; SD: standard deviation 


\begin{tabular}{|c|c|c|c|}
\hline Variables & Odds Ratio & Confidence interval & P-value \\
\hline Body mass index (BMI) kg/m² & 0.95 & $(0.90-1.01)$ & 0.13 \\
\hline Total dose of used gonadotropins & 1.008 & $(0.98-1.02)$ & 0.41 \\
\hline History of previous ART cycle & 0.94 & $(0.80-1.09)$ & 0.43 \\
\hline Women age & 0.91 & $(0.87-0.95)$ & 0.01 \\
\hline Women age groups & & & 0.001 \\
\hline$<35$ years & Reference group & & \\
\hline$\leq 35$ years & 0.44 & $(0.28-0.71)$ & \\
\hline Reason of infertility (Mixed factors ) & Reference group & & \\
\hline Ovulatory Factor & 0.68 & $(0.40-1.17)$ & 0.17 \\
\hline Male factor & 1.34 & $(0.73-2.45)$ & 0.3 \\
\hline Type of infertility (secondary) & 1.00 & $(0.58-1.71)$ & 0.99 \\
\hline Duration of infertility & 0.95 & $(0.90-1.01)$ & 0.12 \\
\hline Total number of retrieved oocytes & 1.25 & $(1.12-1.40)$ & $<0.001$ \\
\hline Number of Mll oocytes & 1.28 & $(1.12-1.45)$ & $<0.001$ \\
\hline Number of $2 \mathrm{PN}$ & 1.41 & $(1.21-1.65)$ & $<0.001$ \\
\hline Number of obtained embryos & 1.38 & $(1.15-1.65)$ & $<0.001$ \\
\hline Quality of embryos (Fair) & Reference group & & \\
\hline Quality of embryos (Excellent) & 7.46 & $(2.26-24.53)$ & 0.0009 \\
\hline Quality of embryos (Good) & 4.82 & $(1.42-16.40)$ & 0.01 \\
\hline Day of ET (cleavage stage) & 0.96 & $(0.48-1.92)$ & 0.91 \\
\hline Number of ET & 1.6 & $(1.19-2.19)$ & 0.001 \\
\hline Endometrial thickness on ET day & 1.06 & $(0.92-1.22)$ & 0.37 \\
\hline $\mathrm{AMH}(\mathrm{ng} / \mathrm{ml})$ & 0.85 & $(0.55-1.31)$ & 0.48 \\
\hline $\begin{array}{l}\text { AMH group } \\
\text { AMH > } 0.5(\mathrm{ng} / \mathrm{ml})\end{array}$ & \multicolumn{2}{|c|}{$\mathrm{AMH}>0.5(\mathrm{ng} / \mathrm{ml})$} & 0.7 \\
\hline $\mathrm{AMH} \leq 0.5(\mathrm{ng} / \mathrm{ml})$ & 0.93 & $(0.58-1.48)$ & \\
\hline Basal serum LH & 1.04 & $(0.96-1.11)$ & 0.26 \\
\hline
\end{tabular}




\begin{tabular}{|llll|}
\hline Basal serum FSH & 1.02 & $(0.96-1.08)$ & 0.37 \\
\hline Basal serum TSH & 0.74 & $(0.58-0.96)$ & 0.02 \\
\hline POSEIDON groups & Reference group & & \\
POSEIDON group (4) & & & 0.99 \\
\hline POSEIDON group (1) & 0.9 & $(0.36-2.70)$ & 0.57 \\
\hline POSEIDON group (2) & 0.7 & $(0.23-2.05)$ & 0.0003 \\
\hline POSEIDON group (3) & 2.5 & $(1.51-4.12)$ & 0.38 \\
\hline Type embryo transfer (FET) & 1.267 & $(0.74-2.16)$ & \\
\hline Type of COH protocol & & & 0.18 \\
\hline Long agonist & Reference group & & 0.31 \\
\hline Antagonist & 0.71 & $(0.42-1.17)$ & 0.70 \\
\hline Double-stimulation & 0.69 & $(0.33-1.41)$ & \\
\hline Mini-flare & 0.6 & $(0.07-5.68)$ & 0.471 \\
\hline Bologna groups & & & 0.161 \\
\hline (Phenotype V) & Reference group & & 0.893 \\
\hline Phenotype I & 0.184 & $(0.01-1.96)$ & $(0.25-4.84)$ \\
\hline Phenotype II & 1.106 & $(0.44-5.69)$ & \\
\hline Phenotype III & 1.596 & $(0.09-1.97)$ & \\
\hline Phenotype IV & 0.428 & & \\
\hline
\end{tabular}


Table Vl: The multivariate logistic regression (by backwards manner) analysis to determine the predictive variables of the live birth in the studied population $(n=812)$

\begin{tabular}{|llll|}
\hline Variables & Odds Ratio & Confidence interval & P-value \\
\hline $\begin{array}{l}\text { Quality of transferred embryos } \\
\text { Fair }\end{array}$ & Reference group & & - \\
\hline Excellent & 5.96 & $(1.7-20.47)$ & \\
\hline Good & 4.56 & $(1.2-16.13)$ & $\mathbf{0 . 0 0 5}$ \\
\hline Number of transferred embryos & 1.608 & $(1.09-2.35)$ & $\mathbf{0 . 0 1 8}$ \\
\hline POSEIDON group 4 & Reference group & & $\mathbf{0 . 0 1 5}$ \\
\hline POSEIDON group 1 & 1.73 & $(087-5.139)$ & - \\
\hline POSEIDON group 2 & 0.63 & $(0.1-2.327)$ & 0.317 \\
\hline POSEIDON group 3 & 3.04 & $(1.6-5.634)$ & 0.496 \\
\hline
\end{tabular}

